\title{
Detection of 5-hydroxymethylfurfural and furfural in the aerosol of electronic cigarettes
}

\author{
Sarah Soussy, ${ }^{1,2}$ Ahmad EL-Hellani, ${ }^{1,2}$ Rima Baalbaki, ${ }^{1,2}$ Rola Salman, ${ }^{2,3}$ \\ Alan Shihadeh, ${ }^{2,3}$ Najat A Saliba ${ }^{1,2}$
}

- Additional material is published online only. To view please visit the journal online (http://dx.doi.org/10.1136/ tobaccocontrol-2016-053220).

${ }^{1}$ Faculty of Arts and Sciences, Chemistry Department, American University of Beirut, Beirut, Lebanon

${ }^{2}$ Center for the Study of Tobacco Products, Virginia Commonwealth University, Richmond, Virginia, USA ${ }^{3}$ Faculty of Engineering and Architecture, Mechanical Engineering Department, American University of Beirut, Beirut, Lebanon

\section{Correspondence to}

Professor Najat A Saliba, Faculty of Arts and Sciences, Chemistry Department, American University of Beirut, Riad El Solh, Beirut 1107 2020, Lebanon; ns30@aub.edu.lb

Received 1 June 2016 Accepted 5 October 2016

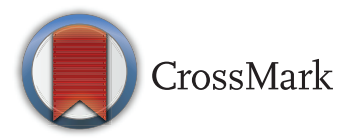

To cite: Soussy S,

EL-Hellani A, Baalbaki R, et al. Tob Control 2016;25 ii88-ii93.

\begin{abstract}
Significance The wide availability of sweet flavours has been hypothesised as a factor in the popularity of electronic cigarette $(E C I G)$, especially among youth. Saccharides, which are commonly used to impart a sweet flavour to ECIG liquids, thermally degrade to produce toxic compounds, like aldehydes and furans. This study investigates the formation of furanic compounds in aerosols when ECIG liquid solutions of varying sweetener concentrations are vaped under different power and puff duration.
\end{abstract}

Methods Liquids are prepared by mixing aqueous sucrose, glucose or sorbitol solutions to a 70/30 propylene glycol/glycerin solution. Aerosols are generated and trapped on filter pads using a commercially available ECIG operating at 4.3 and $10.8 \mathrm{~W}$ and 4 and $8 \mathrm{~s}$ puff duration. Extraction, elimination of matrix interference and quantification are achieved using novel solid phase extraction and gas chromatography tandem mass spectrometry methods (GC-MS).

Results Well-resolved GC peaks of 5hydroxymethylfurfural (HMF) and furfural (FA) are detected. Both HMF and FA are quantified in the aerosols of sweet-flavoured e-liquids under various vaping conditions. Levels of furan emissions are significantly correlated with electric power and sweetener concentration and not with puff duration. Unlike saccharides, the formation of HMF and FA from a sugar alcohol is negligible.

Conclusions The addition of sweeteners to ECIG liquids exposes ECIG user to furans, a toxic class of compounds. Under certain conditions, the per-puff yield of HMF and FA in ECIG emissions is comparable to values reported for combustible cigarettes.

\section{INTRODUCTION}

Electronic cigarette (ECIG) use has rapidly become a global epidemic. ${ }^{1-4}$ Between 2013 and 2014, ECIG use has tripled among middle and high school students and surpassed current use of tobacco products. ${ }^{5-7}$ Besides the wide availability, ${ }^{8-10}$ media advertisements ${ }^{11} 12$ and social acceptability, the high prevalence of ECIG use among youth has been attributed to the wide variety of available flavours. ${ }^{13} 14$

The ECIG basic design consists of a battery, electrical heating coil and e-liquid reservoir. ${ }^{15}$ ECIGs vapourise a liquid composed of varying ratios of propylene glycol (PG), glycerin (VG), water, nicotine $(0-48 \mathrm{mg} / \mathrm{mL})$ and additives, including flavourants. ${ }^{16}$ The efficacy of ECIG nicotine delivery has evolved with design and user behaviour over the years. ${ }^{17}{ }^{18}$ Along with nicotine, e-liquids can be contaminated with nitrosamines, volatile organic compounds or metals leached from the different metallic components. ${ }^{19}{ }^{20}$ Other toxicants, which are generated from the thermal degradation of the heated liquid, ${ }^{21}$ are referred to as "vaping toxicants'. One group of vaping toxicants is reactive oxygen species that are generated from the cleavage of chemical bonds. ${ }^{22}$ Another group is carbonyls which may be the most studied toxicants in ECIG vapours after nicotine. ${ }^{23}$ Studies have reported widely varying carbonyl yields, ${ }^{24}$ with some exceeding those reported for combustible cigarettes. ${ }^{25}$ Produced carbonyls in ECIG aerosol was anticipated from the investigation of PG and VG pyrolysis in food chemistry and biomass fuel generation. ${ }^{26}{ }^{27}$ Flavourants may present another potent source of 'vaping toxicants'. ${ }^{28}$

In the ECIG market, there are more than 7000 different liquid flavours. ${ }^{29-31}$ Whether flavours enhance ECIG appeal to smokers and thereby reduce overall consumption of combustible cigarettes, ${ }^{32-34}$ or serve to initiate nicotine-naïve individuals and thereby increase overall use of combustible products $^{35-38}$ remains a controversial topic. In 2009, the US Food and Drug Administration (FDA) banned tobacco cigarettes with characterising flavours because of their appeal to youth.

Several studies have reported toxicant emissions from flavoured ECIGs. ${ }^{28} 39{ }^{40}$ Flavourants may be grouped into a number of categories, one of which catalogues six common groups: tobacco, menthol, fruits, beverages, sweet flavours and others. ${ }^{28}$ The 'sweet' category, which is popular among ECIG users, ${ }^{7}$ lists sugar, caramel and honey as advertised ingredients. ${ }^{41}$ The thermal degradation of sugars has been reported to yield toxic furans including 5-hydroxymethylfurfural (HMF) and furfural (FA). ${ }^{42}{ }^{43}$ FA causes irritation to the upper respiratory tract in humans, ${ }^{44}$ and both FA and HMF show tumourigenic activity in mice. ${ }^{45-47}$

In this study, we examined whether vaping laboratory-prepared sucrose, glucose and sorbitol containing e-liquid solutions can produce significant levels of HMF and FA. To do so, a novel analytical clean-up procedure gas chromatography tandem mass spectrometry (GC-MS) method was developed and optimised. Using this method, the influence of puff duration, power and sugar concentration on the yield of these toxicants was evaluated.

\section{MATERIALS AND METHODS}

Liquids with various concentrations of sucrose, glucose or sorbitol were prepared in a 70/30 PG/ VG ratio, and vaped under variable ECIG electrical power and puff duration. The analysis of HMF and 
FA in aerosols by GC-MS necessitated the optimisation of a new extraction procedure to separate furans from PG and VG using solid phase extraction (SPE).

\section{Materials}

SPE cartridges $(1000 \mathrm{mg} / 6 \mathrm{~mL}$ Hypersep si) and quartz filters (Advantec, QR-100, $47 \mathrm{~mm}$ ) were procured from Thermo Fisher Scientific and Whatman International, respectively. High-performance liquid chromatography-grade ethyl acetate, hexane, chloroform and acetonitrile, PG (99.5\%), VG (99$101 \%$ ), and HMF analytical standard were obtained from Sigma Aldrich. FA and internal standard (5-chloro-2-furfural) were obtained from Absolute Standards. Glucose, sorbitol and sucrose were food grade products provided by the Faculty of Agricultural and Food Sciences at the American University of Beirut (AUB).

\section{Liquid preparation}

E-liquid of 70/30 PG/VG ratio was used because it is commonly found in ECIG products. Stock solutions of sucrose, glucose and sorbitol in distilled water were prepared with 345, 442 and $243(\mathrm{mg} / \mathrm{mL})$ concentrations, respectively. Subsequently, $0.5 \mathrm{~mL}$ of each stock solution was added to $10 \mathrm{~mL}$ of the PG/VG mixture. The percentage of sugar in the prepared liquids (1.01-1.91 wt $\%$ equivalent to $11-21 \mathrm{mg} / \mathrm{mL}$ ) was chosen to be in the range of commercially reported concentrations $\left(1-4 \mathrm{wt}^{2}\right){ }^{28}$ Four concentrations of $0.03,0.25,0.63,1.23$ $\mathrm{wt} \%$ were prepared and sonicated for 2 hours to ensure homogeneity.

\section{Aerosol generation and sampling}

Aerosols were generated from a custom-designed digital puff production machine at $\mathrm{AUB}^{48}$ using the commercial brand VaporFi PLATINUM II Tank (VP). ${ }^{49}$ This model was selected because it represents a common 'tank' system in which liquid is conducted from the reservoir via a short wick to the heating coil.

Aerosols were generated at 4.3 and $10.8 \mathrm{~W}$, representing a typical and higher than average power input (operating ranges of $3-15 \mathrm{~W}$ are common). ${ }^{50}$ In addition to power, the effects of two puff durations ( 4 or $8 \mathrm{~s}$ ) and sucrose concentrations were assessed. Electrical resistances of the ECIG atomisers, which were measured before and after each use, were $2.3 \pm 0.11 \Omega$.

Aerosols were generated at a constant puff velocity of $1 \mathrm{~L} / \mathrm{min}$ and an inter puff interval of $10 \mathrm{~s}$. Produced aerosols were drawn from the mouth end of the ECIG device, and collected through a quartz fiber filter.

\section{Study design}

Variables included power input ( 4.3 vs $10.8 \mathrm{~W})$, puff duration (4 vs 8 s), sugar (sorbitol, glucose and sucrose) and sucrose concentration $(0,0.03,0.25,0.63,1.23 \mathrm{wt} \%)$. To control for potential interactions with ECIG age and manufacturing variability, three devices of the same make and model were used, and the experimental condition orders randomised. Results of three atomisers were averaged for any given experimental condition.

\section{Analytical procedure}

Filter extraction

The quartz filter loaded with ECIG aerosols is transferred to a glass vial $(4 \mathrm{~mL})$ and subsequently extracted with $2 \mathrm{~mL}$ of ethyl acetate after $30 \mathrm{~min}$ sonication. The filter is removed and the extract is concentrated at room temperature under nitrogen flow (5 L/min) to $0.5 \mathrm{~mL}$.

\section{SPE clean-up operating procedure}

The clean-up method is optimised using standard solutions of HMF and FA prepared in PG/VG matrix of 70/30 ratio. SPE is conditioned using $10 \mathrm{~mL}$ hexane, the concentrated sample is loaded and the elution solvent is optimised (chloroform/acetonitrile: $8.5 / 1.5 \mathrm{~mL}$ ) to retain PG and VG while eluting HMF and FA at high recovery. The eluted solution is concentrated down to $0.5 \mathrm{~mL}$ under nitrogen flow. The sample is spiked with 5-chloro-2-furfural $(4 \mu \mathrm{g} / \mathrm{mL})$ as internal standard (IS) before injection to GC-MS.

\section{Quality control and quality assurance}

The repeatability of the method is evaluated by carrying out six replicate extractions of 5,40 and $120 \mu \mathrm{g} / \mathrm{mL}$. The maximum \% relative standard deviation (RSD) is $15 \%$ and $3 \%$ for HMF and FA, respectively. The recovery of the method at 5 and $40 \mu \mathrm{g} / \mathrm{mL}$ is $90 \%$ for HMF and $60 \%$ for FA. Limits of detection and quantification, which are assessed using seven replicates, are $0.05 \mu \mathrm{g} /$ $\mathrm{mL}$ for HMF and $0.2 \mu \mathrm{g} / \mathrm{mL}$ for FA and $0.1 \mu \mathrm{g} / \mathrm{mL}$ for HMF and $0.7 \mu \mathrm{g} / \mathrm{mL}$ for $\mathrm{FA}$, respectively. The quantitative analysis is carried out using an extracted calibration curve with a linear range of $0.1-100 \mu \mathrm{g} / \mathrm{mL}$ for $\mathrm{HMF}$ and $0.8-20 \mu \mathrm{g} / \mathrm{mL}$ for FA. The corresponding regression coefficients are higher than 0.995 .

\section{GC-MS conditions}

The GC-MS analysis is achieved on a Thermo-Finnigan Trace GC-Ultra Polaris ITQ 900 coupled with an AS 3000 II autosampler. A separation TraceGOLD-5MS (TG-5MS) column (60 $\mathrm{m} \times 0.25 \mathrm{~mm}, 0.25 \mu \mathrm{m}$ film thickness) and electron impact

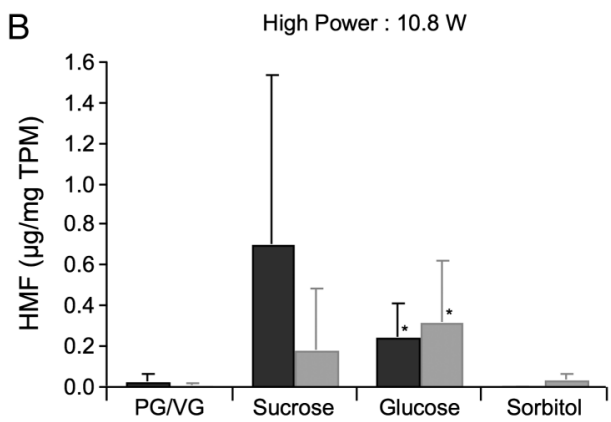

Figure 1 Average HMF yield normalised by TPM $(\mu \mathrm{g} / \mathrm{mg})$ in aerosols generated from laboratory-prepared sucrose, glucose and sorbitol liquids vaped at $4.3 \mathrm{~W}(\mathrm{~A})$ and $10.8 \mathrm{~W}(\mathrm{~B})$ and at 8 and $4 \mathrm{~s}$. ${ }^{*}$ and ${ }^{* *}$ indicate significant difference from the unflavoured liquid at $\mathrm{p}<0.05$ and $\mathrm{p}<0.01$, respectively. $\mathrm{N}=3$ measurements for each condition. $\mathrm{FA}$, furfural; HMF, 5-hydroxymethylfurfural; PG, propylene glycol; TPM, total particulate matter; VG, glycerin. 

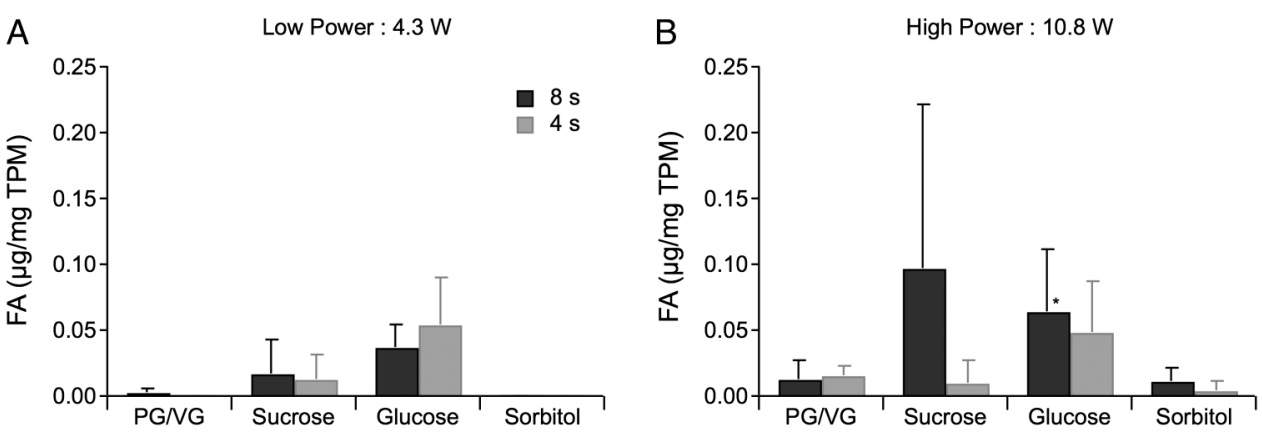

Figure 2 Average FA yield normalised by TPM $(\mu \mathrm{g} / \mathrm{mg})$ in aerosols generated using sucrose, glucose and sorbitol-containing liquids vaped at $4.3 \mathrm{~W}(\mathrm{~A})$ and $10.8 \mathrm{~W}(\mathrm{~B})$. * indicates significant difference from the unflavoured liquid at $\mathrm{p}<0.05 . \mathrm{N}=3$ measurements for each condition. $\mathrm{FA}$, furfural; HMF, 5-hydroxymethylfurfural; PG, propylene glycol; TPM, total particulate matter; VG, glycerin.

ionisation with nominal electron energy of $70 \mathrm{eV}$ are used. The mobile phase is helium gas of $99.999 \%$ purity with a $1 \mathrm{~mL} / \mathrm{min}$ flow rate. The mode of injection is splitless. The injector temperature is set at $200^{\circ} \mathrm{C}$. The initial temperature was $40^{\circ} \mathrm{C}$, hold for $1 \mathrm{~min}$, ramping at $30^{\circ} \mathrm{C} / \mathrm{min}$ to $80^{\circ} \mathrm{C}$, at $15^{\circ} \mathrm{C} / \mathrm{min}$ to $150^{\circ} \mathrm{C}$ and then at $20^{\circ} \mathrm{C} / \mathrm{min}$ to $220^{\circ} \mathrm{C}$. The quantitative analysis is performed using selected ion mass $(\mathrm{m} / \mathrm{z}=97,96$ and 129 for HMF, FA and IS, respectively).

\section{Statistical analysis}

The effect of the power, puff duration and sweetener concentration on HMF and FA yields was assessed by a two-tailed distribution and heteroscedastic t-test.

\section{RESULTS}

Both HMF and FA were reliably detected in the generated aerosols. Figures 1 and 2 show the average levels of HMF and FA per mg of total particulate matter (TPM). FA yields were considerably lower than HMF under all conditions. Prior to vaping, all liquids showed no detectable quantities of furans. Battery power output revealed a significant effect on the TPM normalised yields of HMF generated from sucrose $(\mathrm{p}<0.01)$ and glucose $(\mathrm{p}<0.02)$. In particular, $4.3 \mathrm{~W}$ generated higher HMF concentrations than $10.8 \mathrm{~W}$. FA concentrations appear to show an opposite trend, with greater power resulting in larger yields; however, the large variances in repeated measures rendered the differences statistically insignificant, except for the glucose condition with an $8 \mathrm{~s}$ puff duration.

Relative to the unflavoured conditions, the sucrose and glucose conditions generally had greater HMF and FA concentrations, while the sorbitol conditions showed similar results. At
4.3 W (figure 1A), these differences in HMF of sucrose and glucose were significant, while those for the sorbitol condition were not. Similar trends were observed at $10.8 \mathrm{~W}$ (figure 1B); however, HMF yields for the sucrose condition were not significantly different from the unflavoured condition due to the large variance in repeated measures. In a similar comparison, sorbitol produced no significant change in FA (figure 2), while the sucrose and glucose conditions appear to have greater yields. Only the $8 \mathrm{~s}$ puff duration and $10.8 \mathrm{~W}$ glucose condition demonstrated a statistically significant difference. Unlike power, puff durations have generated similar levels of furans. Furthermore, both HMF and FA aerosol show a significant correlation with sucrose concentration at both puff durations $(\mathrm{p}<0.01$ and $\mathrm{p}<0.001$ at $4 \mathrm{~s}$, and $\mathrm{p}<0.01$ and $\mathrm{p}<0.001$ at $8 \mathrm{~s}$ for HMF and FA, respectively; figure 3 ).

To validate the method on a commercial ECIG matrix, a flavoured Vapor Fi was selected and spiked with a known concentration of sucrose $(13 \mathrm{mg} / \mathrm{mL}$, equivalent to $1.23 \%)$. Three replicate solutions were vaped at $5.0 \mathrm{~W}$ during a $4 \mathrm{~s}$ puff duration. Aerosols average concentrations (ng/mg) of HMF (4.26 $\pm 1.15)$ and FA $(191.47 \pm 62.55)$ were comparable to what is reported for the standard solutions. Chromatograms of the spiked commercial e-liquid show no interferences preventing the detection and quantification of furan compounds.

\section{DISCUSSION}

The thermal decomposition of saccharide molecules such as sucrose, glucose and fructose has been under intense focus for its wide application in food $^{51-53}$ and as an alternate renewable energy source. ${ }^{54-56}$ Hence, many studies have reported HMF as a product of the caramelisation process ${ }^{57-60}$ and both HMF and
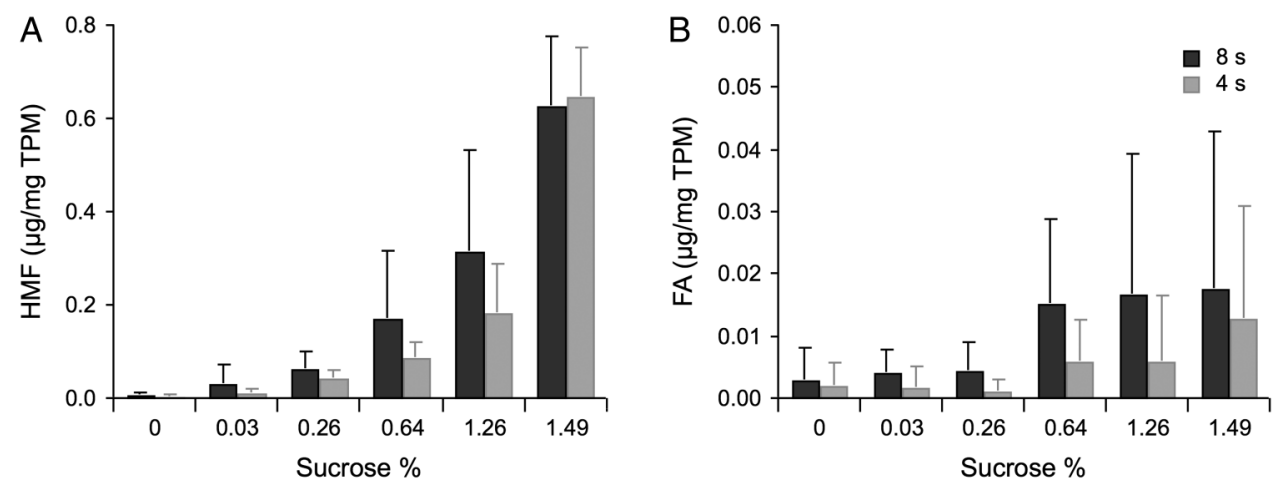

Figure 3 Average level $(\mu \mathrm{g} / \mathrm{mg})$ of $\operatorname{HMF}(A)$ and $F A(B)$ in the aerosol generated from different concentrations of sucrose in the e-liquid $(n=3$ per condition). FA, furfural; HMF, 5-hydroxymethylfurfural. 

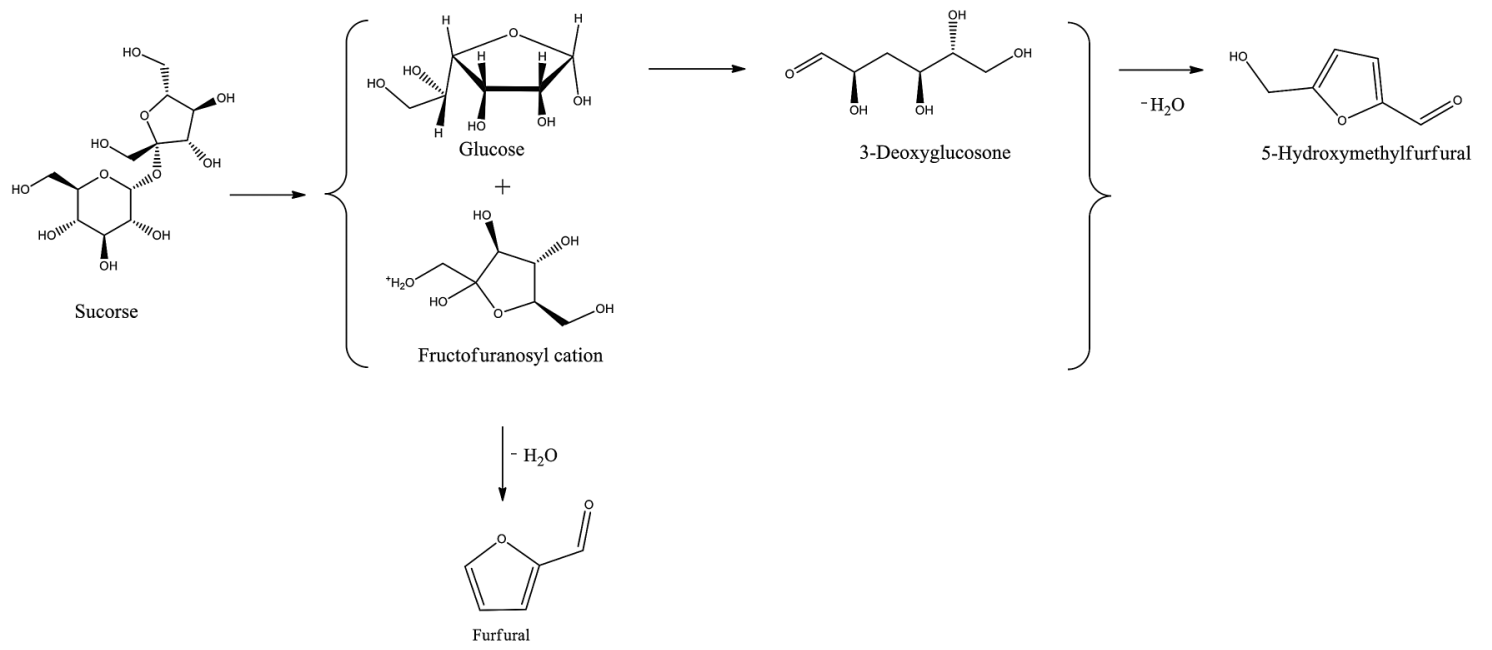

Figure 4 A plausible pathway for the saccharide dehydration.

FA as thermal decomposition products under different type of catalysts, temperature and pressure. ${ }^{61-67}$ Owing to the high functionalisation of sugar molecules, the decomposition mechanism is thought to involve many side reactions, ${ }^{6-70}$ with HMF being thermally generated from sucrose through the formation of fructofuranosyl cation and from glucose through the cyclisation of 3-deoxyglucosone intermediates. FA is formed via an additional dehydration product from the thermal decomposition of sugar molecules as shown in figure $4 . .^{71-74}$

In ECIG systems, the presence of sucrose in some sweet commercial brands has been reported. ${ }^{75}$ Our results show that HMF and FA are formed when sucrose and glucose-containing liquids are vaped. Minimal amounts, however, are produced with sorbitol-containing liquids. Interestingly, lower battery power led to higher HMF concentrations but lower FA concentrations. This finding complicates the commonly held notion that lower power output leads to lower heating filament temperatures and, therefore, lower emissions of toxicants, which are formed by thermal degradation, such as volatile aldehydes. ${ }^{24} 48$

Variances in repeated measures of HMF and FA were far greater at higher power conditions. Such variability may have been induced by the occurrence of hot spots on the heating element where contact with the liquid-supplying wick was poor. These variations are comparable to those previously observed with aldehydes in ECIG aerosols. ${ }^{21}$ 76-79

HMF and FA yields were also dependent on the initial sucrose concentration. However, the non-linear correlation between sucrose and the furan products (HMF and FA) indicates that the mechanism of formation of furans is complex. ${ }^{80}$ So, in addition to the initial sucrose concentration, the degradation of sugar might be influenced by factors like the condition of the

Table 1 The range of HMF and FA aerosol concentrations per puff in ECIG, tobacco cigarette and water pipe

\begin{tabular}{lllll}
\hline & ECIG & CIG & WPS & References \\
\hline $\begin{array}{l}\text { Sugar content } \\
\text { (\% by mass) }\end{array}$ & $0.03-1.91$ & $0.21-22.09$ & $50-70$ & This study ${ }^{57-59}$ \\
HMF ( $\mu$ g/puff) & $0.07-19.1$ & $0.0-11$ & $14.1-364.3$ & This study 8182 \\
FA ( $\mu$ g/puff) & $0.01-2.6$ & $0.0-2.9$ & $0.2-2.3$ & This study ${ }^{5182}$ \\
\hline
\end{tabular}

ECIG, electronic cigarette; FA, furfural; HMF, 5-hydroxymethylfurfural. coil, the maximum temperature reached during its activation and the multistep mechanism of furan formation.

Considering the full range of the aerosol furan content independent of the power, the puff duration, and the sugar type and concentration (see online supplementary table S1), the exposure level per puff of ECIG was compared with the aerosol levels in tobacco cigarette and water pipe smoke (WPS) as shown in table 1. It is found that ECIG users are exposed to HMF and FA levels similar to the ones reported for a combustible cigarette and to the lower limits of water pipe smoke. Exposure to HMF and FA raises several health concerns. The potential mutagenic activity of HMF is attributed to one of its major toxin metabolites known as 5-sulfoxymethylfurfural. ${ }^{46}{ }^{47}$ As for FA, clear evidence for carcinogenic activity and histopathological changes in the respiratory epithelium of mice have been reported. ${ }^{45} 44$

Results indicate that potential toxicants are produced at concentrations lower than $0.26 \%$, and therefore limits on the type and content of sweet flavourants can be recommended. In addition, increased emission in relation to power and puff duration calls for stringent regulations on the ECIG design.

\section{CONCLUSION}

This study focuses on developing an analytical method to isolate furans from the PG/VG matrix and assessing the emission of toxic furans from sweet-flavoured ECIG solutions. Vaped under different conditions, the levels of furans are found to be significantly different from the PG/VG base solutions and are correlated with battery power output and sugar concentration. Surprisingly, no significant difference in yields was observed

\section{What this paper adds}

The market of electronic cigarette has globally exploded with the introduction of a wide range of flavourants. This comes at a time when regulations and potential risk studies are still scarce. This paper assessed the production of furans from sweetened e-liquids. A systematic approach is taken to study the effect of power, puff duration and sweetener type and percentage on the yield of furans. A novel clean-up procedure is developed followed by quantification via a new gas chromatography tandem mass spectrometry method. 
between the 4 and $8 \mathrm{~s}$ puff durations. Per-puff emissions of HMF and FA from ECIGs using sweetened solutions were comparable to those found in cigarette and water pipe smoke, suggesting that sugar-based additives in ECIG solutions be regulated.

Funding Research reported in this publication was supported by the National Institute on Drug Abuse of the National Institutes of Health under Award Number P50DA036105 and the Center for Tobacco Products of the US Food and Drug Administration.

Disclaimer The content is solely the responsibility of the authors and does not necessarily represent the official views of the National Institutes of Health or the Food and Drug Administration.

Competing interests None declared.

Provenance and peer review Not commissioned; externally peer reviewed.

\section{REFERENCES}

1 Adkison SE, O'Connor RJ, Bansal-Travers M, et al. Electronic nicotine delivery systems: international tobacco control four-country survey. Am J Prev Med 2013;44:207-15

2 Pepper JK, Eissenberg T. Waterpipes and electronic cigarettes: increasing prevalence and expanding science. Chem Res Toxicol 2014;27:1336-43.

3 McMillen RC, Gottlieb MA, Shaefer RMW, et al. Trends in electronic cigarette use among U.S. adults: use is increasing in both smokers and nonsmokers. Nicotine Tob Res 2015;17:1195-202.

4 King BA, Patel R, Nguyen $\mathrm{KH}$, et al. Trends in awareness and use of electronic cigarettes among US adults, 2010-2013. Nicotine Tob Res 2015;17:219-27.

5 CDC. E-cigarette use triples among middle and high school students in just one year. 2015. http://www.cdc.gov/media/releases/2015/p0416-e-cigarette-use.html

6 Goniewicz ML, Gawron M, Nadolska J, et al. Rise in electronic cigarette use among adolescents in Poland. J Adolesc Health 2014;55:713-15.

7 Krishnan-Sarin S, Morean ME, Camenga DR, et al. E-cigarette use among high school and middle school adolescents in Connecticut. Nicotine Tob Res 2015; 17:810-18.

8 Huang J, Kornfield R, Szczypka G, et al. A cross-sectional examination of marketing of electronic cigarettes on Twitter. Tob Control 2014;23(Suppl 3):iii26-30.

9 Cobb NK, Brookover J, Cobb CO. Forensic analysis of online marketing for electronic nicotine delivery systems. Tob Control 2015;24:128-31.

10 Hughes $\mathrm{K}$, Bellis MA, Hardcastle KA, et al. Associations between e-cigarette access and smoking and drinking behaviours in teenagers. BMC Public Health 2015:15:1-9.

11 Duke JC, Lee YO, Kim AE, et al. Exposure to electronic cigarette television advertisements among youth and young adults. Pediatrics 2014;134:e29-36.

12 Richardson A, Ganz O, Stalgaitis C, et al. Noncombustible tobacco product advertising: how companies are selling the new face of tobacco. Nicotine Tob Res 2014;16:606-14

13 Trumbo CW, Kim SJS. The effect of electronic cigarette advertising on intended use among college students. Addict Behav 2015;46:77-81.

14 Grana RA, Ling PM. "Smoking revolution": a content analysis of electronic cigarette retail websites. Am J Prev Med 2014;46:395-403.

15 Breland A, Soule E, Lopez A, et al. Electronic cigarettes: what are they and what do they do? Ann N Y Acad Sci Published Online First: 15 Jan 2016. doi:10.1111/ nyas. 12977

16 Etter JF, Zäther $\mathrm{E}$, Svensson S. Analysis of refill liquids for electronic cigarettes. Addiction 2013;108:1671-9.

17 Farsalinos KE, Spyrou A, Tsimopoulou K, et al. Nicotine absorption from electronic cigarette use: comparison between first and new-generation devices. Sci Rep 2014;4:4133.

18 Ramôa CP, Hiler MM, Spindle TR, et al. Electronic cigarette nicotine delivery can exceed that of combustible cigarettes: a preliminary report. Tob Control 2016;25: e6-9.

19 Hutzler C, Paschke M, Kruschinski S, et al. Chemical hazards present in liquids and vapors of electronic cigarettes. Arch Toxicol 2014;88:1295-308.

20 Cheng T. Chemical evaluation of electronic cigarettes. Tob Control 2014;23(Suppl 2):ii11-17.

21 Bekki K, Uchiyama S, Ohta K, et al. Carbonyl compounds generated from electronic cigarettes. Int J Environ Res Public Health 2014;11:11192.

22 Lerner CA, Sundar IK, Yao H, et al. Vapors produced by electronic cigarettes and e-juices with flavorings induce toxicity, oxidative stress, and inflammatory response in lung epithelial cells and in mouse lung. PLOS ONE 2015;10:e0116732.

23 Uchiyama S, Ohta K, Inaba Y, et al. Determination of carbonyl compounds generated from the e-cigarette using coupled silica cartridges impregnated with hydroquinone and 2,4-dinitrophenylhydrazine, followed by high-performance liquid chromatography. Anal Sci 2013;29:1219-22.
24 Kosmider L, Sobczak A, Fik M, et al. Carbonyl compounds in electronic cigarette vapors: effects of nicotine solvent and battery output voltage. Nicotine Tob Res 2014;16:1319-26.

25 Jensen RP, Luo W, Pankow JF, et al. Hidden formaldehyde in e-cigarette aerosols. N Engl J Med 2015;372:392-4.

26 Stein YS, Antal MJJr, Jones M Jr. A study of the gas-phase pyrolysis of glycerol. J Anal Appl Pyrolysis 1983;4:283-96.

27 Díaz E, Sad ME, Iglesia E. Homogeneous oxidation reactions of propanediols at low temperatures. ChemSusChem 2010;3:1063-70.

28 Tierney PA, Karpinski CD, Brown JE, et al. Flavour chemicals in electronic cigarette fluids. Tob Control 2016:25:e10-15.

29 Zhu SH, Sun JY, Bonnevie E, et al. Four hundred and sixty brands of e-cigarettes and counting: implications for product regulation. Tob Control 2014;23(Suppl 3): iii3-9.

30 Nonnemaker J, Kim AE, Lee YO, et al. Quantifying how smokers value attributes of electronic cigarettes. Tob Control 2016;25:e37-43.

31 Oncken CA, Litt MD, McLaughlin LD, et al. Nicotine concentrations with electronic cigarette use: effects of sex and flavor. Nicotine Tob Res 2015;17:473-8.

32 Shiffman S, Sembower MA, Pillitteri JL, et al. The impact of flavor descriptors on nonsmoking teens' and adult smokers' interest in electronic cigarettes. Nicotine Tob Res 2015:17:1255-62.

33 Benowitz NL. Emerging nicotine delivery products. Implications for public health. Ann Am Thorac Soc 2014;11:231-5.

34 Etter JF, Bullen C. Electronic cigarette: users profile, utilization, satisfaction and perceived efficacy. Addiction 2011;106:2017-28.

35 Leone FT, Douglas IS. The emergence of e-cigarettes: a triumph of wishful thinking over science. Ann Am Thorac Soc 2014;11:216-19.

36 Lee S, Grana RA, Glantz SA. Electronic cigarette use among Korean adolescents: a cross-sectional study of market penetration, dual use, and relationship to quit attempts and former smoking. J Adolesc Health 2014;54:684-90.

37 Popova L, Ling PM. Alternative tobacco product use and smoking cessation: a national study. Am J Public Health 2013;103:923-30.

38 Kong G, Morean ME, Cavallo DA, et al. Reasons for electronic cigarette experimentation and discontinuation among adolescents and young adults. Nicotine Tob Res 2014;17:847-54.

39 Behar RZ, Davis B, Wang Y, et al. Identification of toxicants in cinnamon-flavored electronic cigarette refill fluids. Toxicol In Vitro 2014;28:198-208.

40 Farsalinos KE, Kistler KA, Gillman G, et al. Evaluation of electronic cigarette liquids and aerosol for the presence of selected inhalation toxins. Nicotine Tob Res 2014;17:168-74.

41 For example. http://allthejuices.com/juice/rocket-fuel-vapes-bee-sweet; https://www. halocigs.com/southern-classic-eliquid/; http://smokelessimage.com/ry4.html

42 Jing Q, LÜ X. Kinetics of non-catalyzed decomposition of glucose in high-temperature liquid water. Chin J Chem Eng 2008;16:890-4.

43 Fiore A, Troise AD, Ataç Mogol B, et al. Controlling the Maillard reaction by reactant encapsulation: sodium chloride in cookies. J Agric Food Chem 2012;60:10808-14.

44 Arts JHE, Muiiser H, Appel MJ, et al. Subacute (28-day) toxicity of furfural in Fischer 344 rats: a comparison of the oral and inhalation route. Food Chem Toxicol 2004:42:1389-99.

45 U.S. Department of Health and Human Services NTP, NTP TR 382, NIH Publication No. 90-2837. 1990. https://ntp.niehs.nih.gov/ntp/htdocs/lt_rpts/tr382.pdf

46 Surh YJ, Liem A, Miller JA, et al. 5-Sulfooxymethylfurfural as a possible ultimate mutagenic and carcinogenic metabolite of the Maillard reaction product, 5-hydroxymethylfurfural. Carcinogenesis 1994;15:2375-7.

47 Surh YJ, Tannenbaum SR. Activation of the Maillard reaction product 5-(hydroxymethyl)furfural to strong mutagens via allylic sulfonation and chlorination. Chem Res Toxicol 1994;7:313-18.

48 Talih S, Balhas Z, Eissenberg T, et al. Effects of user puff topography, device voltage, and liquid nicotine concentration on electronic cigarette nicotine yield: measurements and model predictions. Nicotine Tob Res 2015;17:150-7.

49 Community QS. V2 Cigs Review and Coupon. 2015. https://quitsmokingcommunity. org/electronic-cigarettes/v2-cigs-review-and-coupon/

50 Vaporfi. All About Variable Voltage/Wattage Electronic Cigarettes. http://www.learn. vaporfi.com/about-variable-e-cigs.php

51 Hodge JE. Dehydrated foods, chemistry of browning reactions in model systems. J Agr Food Chem 1953;1:928-43.

52 Kowalski S, Lukasiewicz M, Duda-Chodak A, et al. 5-Hydroxymethyl-2-furfural (HMF) - heat-induced formation, occurrence in food and biotransformation-a review. Pol J Food Nutr Sci 2013;63:207-25.

53 Sugisawa $\mathrm{H}$. The thermal degradation of sugars. II. The volatile decomposition products of glucose caramel. J Food Sci 1966;31:381-5.

54 Tong $X, M a$ Y, Li Y. Biomass into chemicals: conversion of sugars to furan derivatives by catalytic processes. App/ Catal A Gen 2010;385:1-13.

55 Besson M, Gallezot P, Pinel C. Conversion of biomass into chemicals over metal catalysts. Chem Rev 2014;114:1827-70.

56 Climent MJ, Corma A, Iborra S. Conversion of biomass platform molecules into fue additives and liquid hydrocarbon fuels. Green Chem 2014;16:516-47. 
57 Chen SL, Yang DJ, Chen HY, et al. Effect of hot acidic fructose solution on caramelisation intermediates including colour, hydroxymethylfurfural and antioxidative activity changes. Food Chem 2009;114:582-8.

58 Ameur LA, Trystram G, Birlouez-Aragon I. Accumulation of 5-hydroxymethyl-2-furfural in cookies during the backing process: validation of an extraction method. Food Chem 2006:98:790-6.

59 Quintas MAC, Brandão TRS, Silva CLM. Modelling colour changes during the caramelisation reaction. J Food Eng 2007;83:483-91.

60 Quintas M, Guimarães C, Baylina J, et al. Multiresponse modelling of the caramelisation reaction. Innovative Food Sci Emerg Technol 2007:8:306-15.

61 Asghari FS, Yoshida H. Kinetics of the decomposition of fructose catalyzed by hydrochloric acid in subcritical water: formation of 5-hydroxymethylfurfural, levulinic, and formic acids. Ind Eng Chem Res 2007;46:7703-10.

62 Rasrendra CB, Soetedjo JNM, Makertihartha IGBN, et al. The catalytic conversion of d-glucose to 5-hydroxymethylfurfural in DMSO using metal salts. Top Catal 2012;55:543-9.

63 Tong $X$, Ma Y, Li Y. An efficient catalytic dehydration of fructose and sucrose to 5-hydroxymethylfurfural with protic ionic liquids. Carbohyd Res 2010;345:1698-701.

64 Zhang J, Cao Y, Li H, et al. Kinetic studies on chromium-catalyzed conversion of glucose into 5-hydroxymethylfurfural in alkylimidazolium chloride ionic liquid. Chem Eng J 2014;237:55-61.

65 Qi L, Mui YF, Lo SW, et al. Catalytic conversion of fructose, glucose, and sucrose to 5-(hydroxymethyl)furfural and levulinic and formic acids in $\gamma$-valerolactone as a green solvent. ACS Catal 2014;4:1470-7.

66 Wang T, Glasper JA, Shanks BH. Kinetics of glucose dehydration catalyzed by homogeneous Lewis acidic metal salts in water. App/ Catal A Gen 2015;498:214-21.

67 Bao Q, Qiao K, Tomida D, et al. Preparation of 5-hydroymethylfurfural by dehydration of fructose in the presence of acidic ionic liquid. Catal Commun 2008;9:1383-8.

68 Nikbin N, Caratzoulas S, Vlachos DG. A first principles-based microkinetic model for the conversion of fructose to 5-hydroxymethylfurfural. ChemCatChem 2012;4:504-11.

69 Assary RS, Kim T, Low JJ, et al. Glucose and fructose to platform chemicals: understanding the thermodynamic landscapes of acid-catalysed reactions using high-level ab initio methods. Phys Chem Chem Phys 2012;14:16603-11.
70 Assary RS, Redfern PC, Greeley J, et al. Mechanistic insights into the decomposition of fructose to hydroxy methyl furfural in neutral and acidic environments using high-level quantum chemical methods. J Phys Chem B 2011;115:4341-9.

71 Perez Locas C, Yaylayan VA. Isotope labeling studies on the formation of 5-(hydroxymethyl)-2-furaldehyde (HMF) from sucrose by pyrolysis-GC/MS. J Agric Food Chem 2008;56:6717-23.

72 Román-Leshkov Y, Chheda JN, Dumesic JA. Phase modifiers promote efficient production of hydroxymethylfurfural from fructose. Science 2006;312:1933-7.

73 Antal MJ, Mok WSL, Richards GN. Mechanism of formation of 5-(hydroxymethyl)2-furaldehyde from d-fructose and sucrose. Carbohyd Res 1990;199:91-109.

74 Chheda JN, Roman-Leshkov Y, Dumesic JA. Production of 5-hydroxymethylfurfural and furfural by dehydration of biomass-derived mono- and poly-saccharides. Green Chem 2007:9:342-50.

75 Kubica P, Wasik A, Kot-Wasik A, et al. An evaluation of sucrose as a possible contaminant in e-liquids for electronic cigarettes by hydrophilic interaction liquid chromatography-tandem mass spectrometry. Anal Bioanal Chem 2014; 406:3013-18.

76 Farsalinos KE, Voudris V, Poulas K. E-cigarettes generate high levels of aldehydes only in 'dry puff' conditions. Addiction 2015;110:1352-6.

77 Shihadeh A, Talih S, Eissenberg T. Commentary on Farsalinos et al. (2015) E-cigarettes generate high levels of aldehydes only in 'dry puff' conditions. Addiction 2015;110:1861-2.

78 Guthery W. Emissions of toxic carbonyls in an electronic cigarette. Beit Tabakforschung Int 2016;27:30-7.

79 Gillman IG, Kistler KA, Stewart EW, et al. Effect of variable power levels on the yield of total aerosol mass and formation of aldehydes in e-cigarette aerosols. Regul Toxicol Pharmacol 2016;75:58-65.

$80 \mathrm{Yu} \mathrm{Y,} \mathrm{Wu} \mathrm{H.} \mathrm{Kinetics} \mathrm{and} \mathrm{mechanism} \mathrm{of} \mathrm{glucose} \mathrm{decomposition} \mathrm{in} \mathrm{hot-compressed}$ water: effect of initial glucose concentration. Ind Eng Chem Res 2011;50:10500-8.

81 Matsushima S, Ishiguro S, Sugawara S. Composition studies on some varieties of tobacco and their smoke. I. Major components in smoke condensate. Beitr Tabakforsch Int 1979;10:31-8.

82 Schubert J, Bewersdorff J, Luch A, et al. Waterpipe smoke: a considerable source of human exposure against furanic compounds. Anal Chim Acta 2012;709:105-12. 